\begin{tabular}{|c|c|c|c|}
\hline & PORT SAID ENGINEERING RESEARCH JOURNAL \\
\hline
\end{tabular}

\title{
Factors Affecting the Cost of Construction Materials in Egypt
}

\author{
Mohamed Abdel-Wahab ${ }^{1}$,Ahmed H. Ibrahim², Hassan M. Ibrahim³, and Emad Y. Abdel-Galil 4
}

\begin{abstract}
Construction materials constitute a major cost component in any construction project. The total cost of installed materials (or value of the materials) may be $50 \%$ or more of the total cost. Cost estimating is an assessment of the expected cost of any construction project. The accuracy of such an estimate has a serious effect on the expected profit of the construction contractor. Hence, a certain contingency premium should be added to the base estimate to increase the level of confidence. Such premium is materially affected by many factors. Through this research, the main factors that are expected to affect the accuracy of the construction materials' cost estimate were clearly identified. The numbers of these factors 46 were collected from the literature review. The twelve factors are identified as the most important factors. These factors were: Unsettlement of the local currency in relation to dollar value, fluctuation of price of raw materials, project materials monopoly by some suppliers, fraudulent activities of subcontractors, standard procedure for updating cost information, poor contractor experience for project type, improper planning and errors during construction, engaging in adequate skill on labor, waste control during material usage, location of project, improper construction methods and improper supervision at site and control.
\end{abstract}

Keywords: Construction, Materials, Cost, Pareto.

\section{INTRODUCTION}

Problems related to managing the flow of materials can be found in every organization. The efficient management of materials plays a key role in the successful completion of a project. The control of materials is a very important and vital subject for every company and should be handled effectively for the successful completion of a project. Materials account for a big part of products and project costs. The cost represented by materials fluctuates and may comprise between $20-50 \%$ of the total project cost and sometimes more. Some studies concluded that materials account for around $50-60 \%$ of the project cost (Stukhart 1995) and (Bernold and Treseler 1991).

${ }^{{ }^{I} \text { Civil Engineering Department, Faculty of Engineering, Port Said }}$ University, Port Said,Egypt, E-mail:mohamedabdelwahab73@yahoo.com

${ }^{2}$ Construction Engineering Department, Faculty of Engineering, Zagazig University, zagazig, Egypt, E-mail:mekky69@yahoo.com

${ }^{3}$ Civil Engineering Department, Faculty of Engineering, Port Said University, Port Said, Egypt, E-mail:hi_hgh@yahoo.com

${ }^{4}$ Civil Engineering Department, Faculty of Engineering, Port Said University, Port Said, Egypt, E-mail: emad0057@eng.psu.edu.eg
Materials are critical to the operations in every industry since unavailability of materials can stop production. In addition, unavailability of materials when needed can affect productivity, cause delays and possible suspension of activities until the required material is available.

Unavailability of materials is not the only aspect that can cause problems. Excessive quantities of materials could also create serious problems for managers. Storage of materials can increase the costs of production and the total cost of any project. When there are limited areas available for storage, the managers have to find other alternatives to store the materials until they are needed. Some of these alternatives might require re-handling of materials, which will increase the costs associated with them. Provisions should be taken to handle and store the materials adequately when they are received. Special attention should be given to the flow of materials once they are procured from suppliers.

It is obvious that materials should be obtained at the lowest cost possible to provide savings to the company(Kini 1999). In the late 1970's, construction companies experienced an increase in costs and a decrease in productivity. The owners of these companies thought that these increases in cost were due to inflation and economic problems. Further research concluded that these companies 
were not using their resources efficiently and that the decrease in productivity was also attributable to poor management (Stukhart 1995). Construction material is recognized to be a major component in the construction project cost. Depending on a different projects it is assumed that materials cost can represent from $30 \%$ to $70 \%$ of the total project (Donyavi and Flanagan 2009).

\section{OBJECTIVE AND SCOPE OF THE RESEARCH}

The main objectives of this study are:

1- Identifying factors affecting the accuracy of the construction materials cost estimating process.

2- Determining and testing the severity of factors that affecting the accuracy of the construction materials' cost estimating using analysis of data collected from the questionnaire form.

3- Identifying the most important factors affecting the construction materials cost

This research focuses on building sector of construction projects in Egypt; including the main phase of construction building; skeleton phase in Egypt.

\section{LITERATURE REVIEW}

The cost of materials includes not only the direct cost of the material items, but also any other costs that may be obtained except for labor or equipment for installation. Additional items of cost to be considered are; transportation, sales taxes and freight costs, delivery, storage, sales and other taxes, losses and other factors will be determined.

Rajaprabha identified 44 critical variables affecting the cost of building materials in the construction industry and these were grouped into 8 groups, design related issues, client related issues, contractor related issues, site related issues, labor and equipment related issues, store related issues, external issues and market condition (Rajaprabha, Velumani et al. 2016)

Durdyev identified 56 variables affecting construction productivity and categorized them into 8 factors of internal group and external group (Durdyev and Mbachu 2011).

Enshassi classified factors affecting productivity in the construction projects into 10 groups, namely: factors associated with the internal workforce, factors associated with leadership, factors associated with work motivation factor associated with time, factors associated with materials and equipment, factors related to supervision, factors related to project characteristics, factors related to security, factors related to quality and external factors (Enshassi, Mohamed et al. 2015).

Soekiman identified 113 variables affecting construction labor productivity and these variables were grouped into 15 groups of factors according to their
Characteristics, namely: design, execution plan, material, Labor, equipment, health and safety, supervision, working Time, project factor, quality, financial, leadership and Coordination, organization, owner/consultant and external factor (Rifai and Soekiman 2014).

Nabil Ailabouni identified 32 significant variables affecting the productivity in the construction industry and these were grouped into 4 groups based on their characteristic, namely: environment factors, organizational factors, group dynamics and personal factors(Ailabouni 2010).

El-Kholy identified 44 factors as causes of cost overrun in construction projects (El-Kholy 2015). And more factors were identified as causes of cost overrun in construction materials gathered from literature (Oberlender and Trost 2001, Attalla and Hegazy 2003, Touran 2003, Burroughs and Juntima 2004, Iyer and Jha 2005, Sonmez, Ergin et al. 2007)

\section{METHODOLOGY}

This search is conducted in the following sequence:

1- A literature review carried out to investigate the previous works in this research area.

2- Identification of factors affecting the accuracy of cost estimating of construction materials based on the previous literature review

3- A questionnaire survey carried out to identify the most important factors affecting construction materials cost in the Egyptian construction market.

\section{MAJOR CATEGORIES IDENTIFIED RELATED TO COST OF BUILDING MATERIAL}

The factors that cause the cost overruns in a building project are classified into 8 categories based on the following issues:

Design related issues: Inadequate preconstruction surveyor material, incomplete drawings, unclear specifications, the inability to complete the design at the tender stage, design complexity and design change.

Client-related issues: Additional works at the request of the owner and delay in approval of materials by the client.

Contractor related issues: Improper supervision on site and control, insufficient material handling instructions, engaging inadequate skill of labor, improper construction methods, improper planning and errors during construction, poor contractor experience of project type and fraudulent activities of subcontractors.

Site-related issues: Waste control during material usage, Lack of site storage space, Stealing on site, Unforeseen site condition, Location of project, Shortage of construction materials at site, No adherence to materials standards that 
is stored at the site, Inappropriate / misuse materials, Poor material handling on site, Delay of material delivery to site and Existence of unnecessary materials.

Labor and equipment related issues Obsolete or unsuitable construction equipment, poor technical performance, equipment availability and failure, shortage of site workers, inaccurate prediction of equipment production rate, skilled labor shortage, lack of equipment, lack of maintenance for the equipment, unskilled operators.

Market condition: Scarcity of materials in market, project materials monopoly by some suppliers, unsettlement of the local currency in relation to dollar value, fluctuation of the price of raw materials

External Factors: Problem with neighbors, weather condition.

Estimating process: Availability of productivity standards, availability of cost index's average, relevant experience of estimating team, standard procedure for updating cost information and the method used in determining contingency.

\section{DESIGN OF QUESTIONNAIRE}

The questionnaire is made and, is translated into Arabic for respondents to be much easier and more comprehensive. The questionnaire carries both the instructions and the questions form. A cover page that contains an introduction to explain the idea and the purpose of the survey, as well as the definition of the interested area of study, is given to each respondent along with the questionnaire, aimed at asking the respondents to fill in the needed information. The questionnaire was either picked up on a second visit when the information was filled or received by mail.

The questionnaire was sent to experts who work for either governmental or private contractor and occupy one of the following jobs, Construction project manager, Planner, Cost engineer and site engineer.

Data were collected through the questionnaire that was left to be answered by a key informant. The questionnaire was given to 250 experts, of whom 161 responded

There are three parts to the questionnaire. The first part includes general questions for the participant, for example, name, graduation year, jobs occupied and experience in construction. The second part explains to the participant how to fill in the third part. The third part is the questionnaire form which includes the factors affecting the accuracy of the cost estimate for construction materials. These factors divided into eight main areas. Each area contains a group of factors, which revolve around the same topic. For each factor, the respondents have five options. These are 'very major effects', 'major effects', 'minor effects', 'very minor effects' and 'no effect'. This guarantees that questions about each factor are asked in the same way in each interview. Factors that are considered in the questionnaire revolve around the following areas:

1. Design related issues

2. Client-related issues

3. Contractor related issues

4. Site-related issues

5. Labor and equipment related issues

6. Market condition

7. External issues

8. Estimating process

\section{Sample size}

Part four is reserved for any other factors or comments from a participant point of view.

(Baxter and Bartlett 2001) used the following formula to compute the required sample size for infinite population:

$$
n=\left(\frac{K^{2} x P(1-P)}{E^{2}}\right)
$$

Where,

$\mathrm{N}$ is the required sample size for finite population, $\mathrm{K}$ value equals to 1.645 when confidence level equals to $90 \%, \mathrm{P}$ is the proportion of population, i.e. $\mathrm{P}$ degree of variance between the elements of the population (the critical value of $\mathrm{P}$ is 0.5$), \mathrm{E}$ is the acceptable margin of error $=10 \%$ for confidence $90 \%$. By substituting of these parameters in equation (1), the required sample size of this study of the finite population is 68 as a minimum value.

\section{Data Measurement}

In order to be able to select the appropriate method of analysis, the level of measurement must be understood. For each type of measurement, there is/are an appropriate method/s that can be applied and not others. In this research, ordinal scales were used. Ordinal scale as shown in table 3.6 is a ranking or a rating data that normally use integers in ascending or descending order. The numbers assigned to the important $(1,2,3,4,5)$ do not indicate that the interval between scales are equal, nor do they indicate absolute quantities. They are merely numerical labels. Based on the Likert scale we have the following table (1) (Cheung, Suen et al. 2004);(Iyer and Jha 2005);(Ugwu and Haupt 2007):

Table (1) Ordinal scale used for data measurement

\begin{tabular}{|c|c|c|c|c|c|}
\hline Item & $\begin{array}{c}\text { Very high } \\
\text { important }\end{array}$ & $\begin{array}{c}\text { High } \\
\text { important }\end{array}$ & $\begin{array}{c}\text { Medium } \\
\text { important }\end{array}$ & $\begin{array}{c}\text { Low } \\
\text { important }\end{array}$ & $\begin{array}{c}\text { Very low } \\
\text { important }\end{array}$ \\
\hline Scale & 5 & 4 & 3 & 2 & 1 \\
\hline
\end{tabular}

The relative importance index method (RII) is used here to determine owners, consultants and contractor's perceptions of the relative importance of the key construction materials cost indicators in Egypt. The relative importance index is computed (Cheung, Suen et al. 2004); (Iyer and Jha 2005);(Ugwu and Haupt 2007): 


$$
R I I=\frac{\sum w}{A * N}
$$

Where:

$\mathrm{W}$ is the weight given to each factor by the respondents and ranges from 1 to 5

$\mathrm{A}=$ the highest weight $=5$

$\mathrm{N}=$ the total number of respondents

\section{RESULTS AND DISCUSSIONS}

After the collection of the sample, data analysis was conducted with research instruments such as the Statistical Package for Social Science (SPSS) software. The data from the questionnaires was fed into SPSS software version 24 , and the results were analyzed to determine the major factors. The mean scores were calculated to rank factors affecting of construction materials cost.

The steps undergone for this analysis are given below

Step 1: Statistical analysis was done for each attribute.

Step 2: Bar graph showing mean values was found out.

Step 3: Based on high mean, the ranking of issues found out.

\subsection{Design Related Factors}

It is important to understand that projects are never completed without alterations to the starting documentation. More changes mean more expenses, especially as the project progresses. These problems will eventually cause construction materials cost overruns.

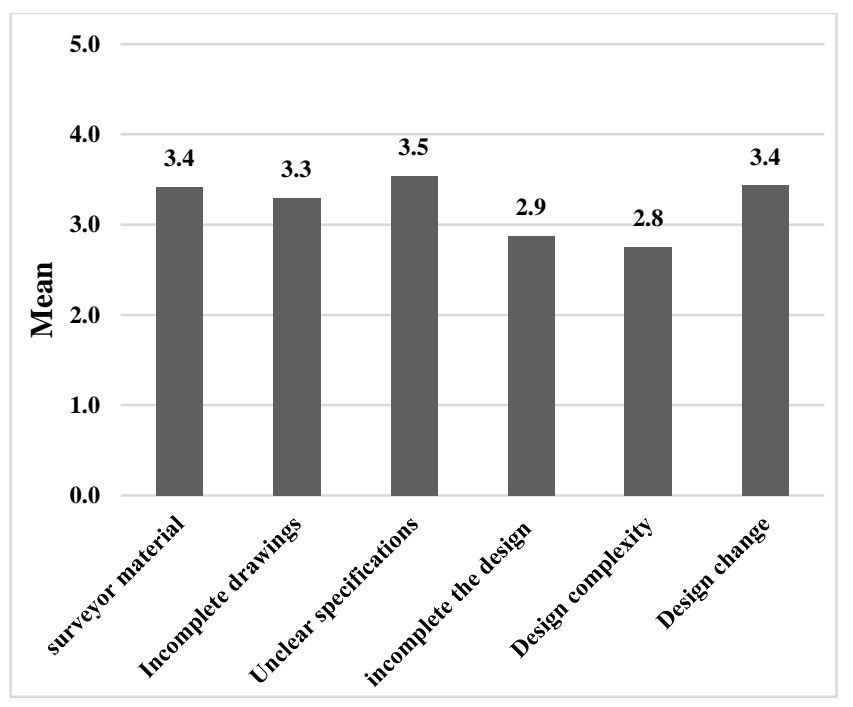

Figure (1) Design Related Factors

Figure (1) indicates that most of the respondents are strongly agree on unclear specifications responsible for cost overrun in construction materials and moderately agree the remaining factors increases the cost, the result of ranking factors indicate unclear specifications has the highest in the ranking of design related factor analysis, Inadequate preconstruction surveyor material and design change ranked the second among the factors outline above, Incomplete drawings that occupied third position in the above the inability to complete the design at the tender stage that occupied fourth position in the above, design complexity that occupied fifth position in the above ranking for factors effect of the construction materials cost.

\subsection{Client Related Factors}

According to the contractors surveyed, delayed progress Payments would affect their project's cash flow as a result Of delayed income. For example, postponing payment to subcontractors \& suppliers, delay in supply of materials, etc., these multiple problems will eventually cause construction delays and cost overruns.

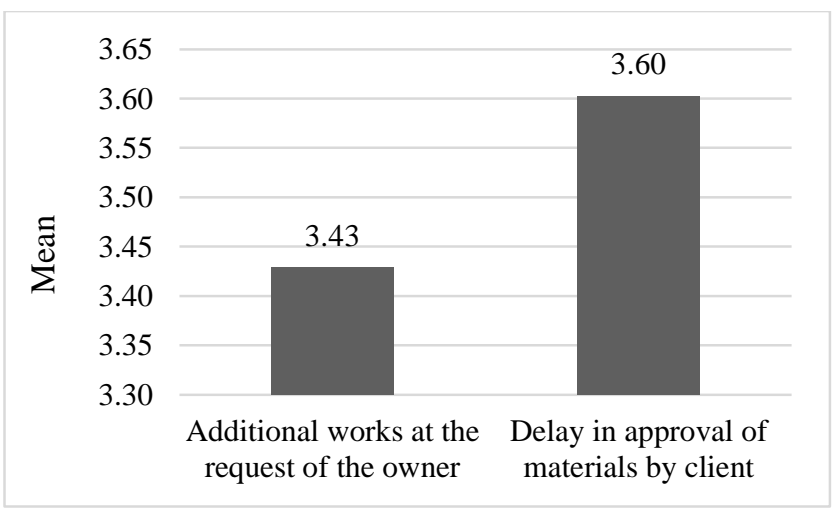

Figure (2) Client Related Factors

Figure (2) indicates that most of the respondents are agreed that delay in approval of materials by client factor will significantly increase the cost and the results indicate most of the respondents moderately delay in approval of materials by client factor is responsible for cost overrun in construction materials and disagree the additional works at the request of the owner factor increases the cost, the result of ranking factors indicate that delay in approval of materials by client has the highest in the ranking of client related factor analysis.

\subsection{Contractor Related Factors}

According to the project managers interviewed, defective works were caused by unskilled labor, lack of supervision, incorrect construction methods and unordered sequences of work. These defective works required extra budgets to complete or repair them. Clearly, this factor would cause construction cost overrun. 


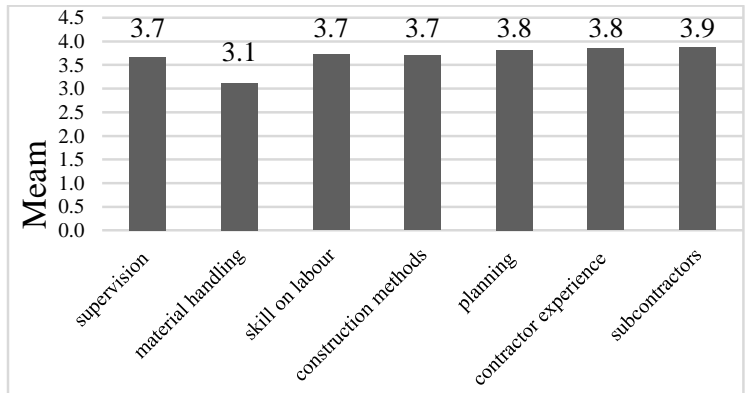

Figure (3) Contractor Related Factors

Figure (3) indicate that most of the respondents are moderately agree that all contractor related factors will significantly increase the cost, and the result of ranking factors indicate that and fraudulent activities of subcontractors has the highest in the ranking of contractor related factor analysis, improper planning, and errors during construction and poor contractor experience for project type both are ranked the second among the factors outline above, Improper supervision at site and control, engaging inadequate skill on labor and improper construction methods all are occupied the third position, insufficient material handling instructions is stands at fourth rank respectively.

\subsection{Site Related Factors}

A major risk in civil engineering project is that the construction may encounter physical conditions on the project site which were unexpected and unforeseeable at the time of making the decision to build the project and which may delay work or cause increased cost. The building construction industry reflects various problems ranging from delays in project execution /delivery, to cost and time overrun as a result of wastages on sites, theft, and displacement of materials on the sites.

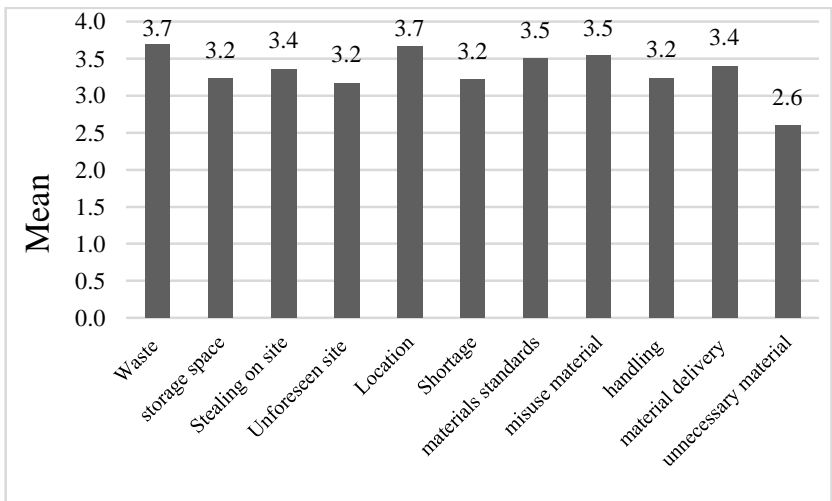

Figure (4) Site Related Factors

Figure (4) indicate that most of the respondents are moderately agree that all site factors except existence of unnecessary material are responsible for cost overrun in construction materials, the result of ranking factors indicate that waste control during material usage and location of project have the highest in the ranking of site- related factor analysis, misuse material and Shortage of construction materials at site both are ranked the second among the issues outlined above, stealing on site and delay of material delivery to site both are occupied the third position, lack of site storage space, unforeseen site condition, shortage of construction materials at site and poor material handling on site all are occupied the fourth position, existence of unnecessary material lies at the fifth position.

\subsection{Labor and Equipment Related Factors}

Unsuitable construction equipment affects the productivity which causes a delay in the project and resulting in cost overrun.

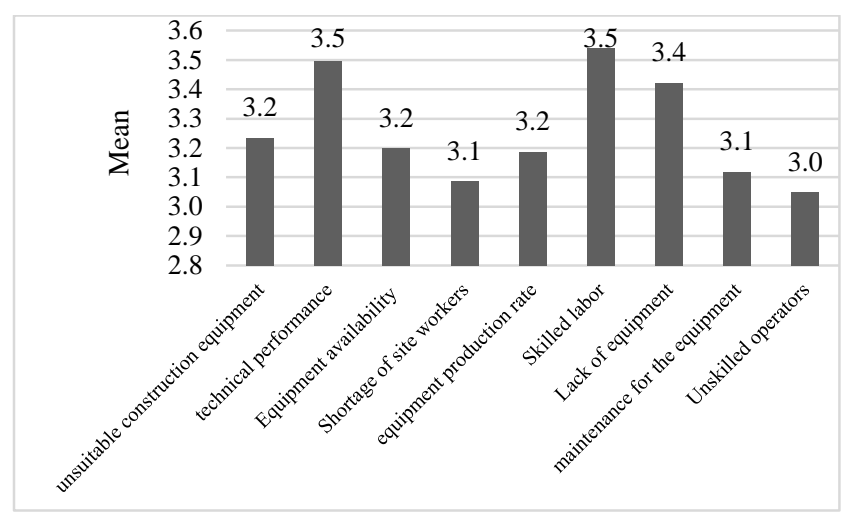

Figure (5)Labor and Equipment Related Factors

Figure (5) indicate that most of the respondents are moderately agree that all labors and equipment are responsible for cost overrun in construction materials, the result of ranking factors indicate that poor technical performance, skilled labor shortage have the highest in the ranking of labor and equipment related factor analysis, lack of equipment is ranked the second among the issues outlined above, obsolete or unsuitable construction equipment, equipment availability and failure, inaccurate prediction of equipment production rate all are occupied the third position, shortage of site workers, lack of maintenance for the equipment both are occupied the fourth position, unskilled operators lie at fifth position.

\subsection{Market Condition Factors}

Inflation has a severe impact on the prices of materials and the monopoly of materials by some suppliers affects the final price of building materials and therefore the whole cost of the project 


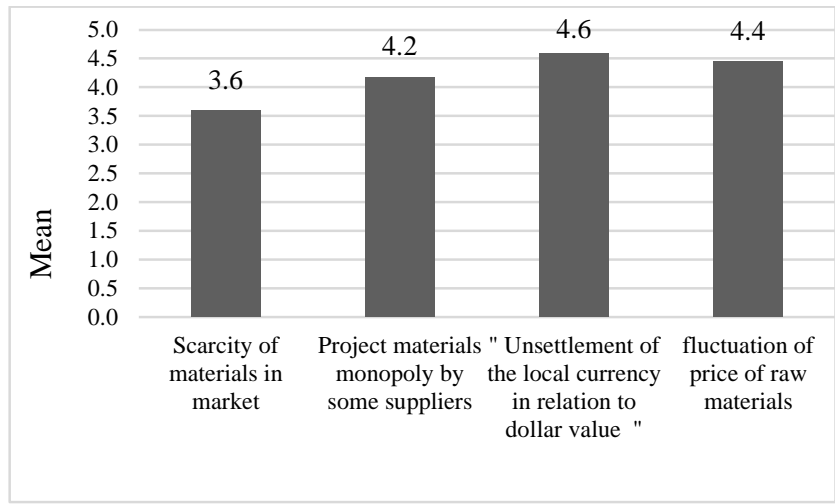

Figure (6) Market Condition Factors

Figure (6) indicate that most respondents strongly agree that commodity unsettlement of the local currency in relation to dollar value is responsible for cost overruns in construction materials while moderately agreeing that the scarcity of materials in the market increases the cost, The result of the ranking factors indicate that the unsettlement of the local currency in relation to dollar value has the highest in the order of analysis of the relevant marketrelated situation factor, raw material prices fluctuate in the second place of the above factors to exceed cost in building materials, the monopoly of construction materials by some suppliers ranked third among the factors listed above, the scarcity of building materials in the market ranked fourth among the factors associated with the market that affect the cost of building materials.

\subsection{External Factors}

Most of the projects surveyed were in the early stages of its cycle, this means that the works being undertaken were foundation work or construction of the building structure. Such activities will certainly be affected by the rain. Project managers whose buildings included basement floors said their basements were flooded and needed more time and equipment to empty them. Most of the concrete work was also affected by heavy rains and in some cases, the casting was postponed. The other effect of the weather was the dumping of sand quarries and therefore weather factors affect the availability of sand.

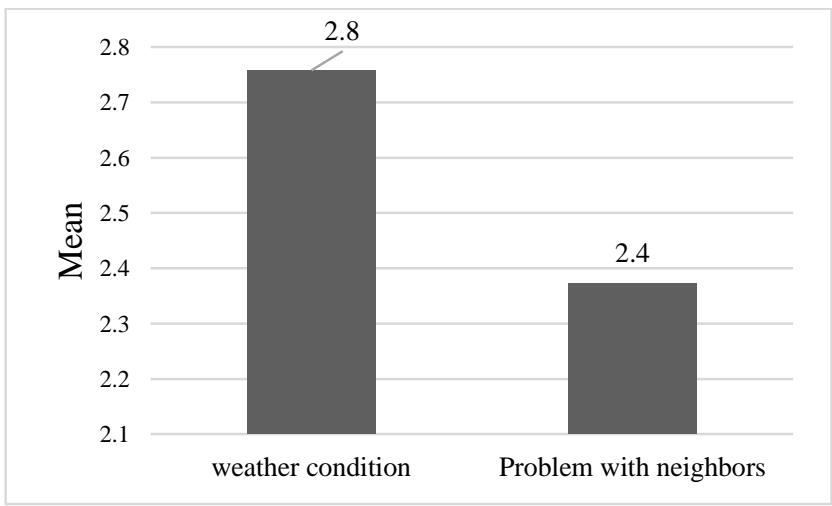

Figure (7) External Factors
Figure (7) indicate that most respondents agree that the external factors mentioned above do not significantly increase the cost. The results indicate that most participants agree moderately that these external factors are not responsible for exceeding the cost of building materials. As a result, the factors indicate that their weather condition is higher in the ranking of external factor analysis, while problems with neighbor ranked second among external factors.

\subsection{Estimating Process Factors}

The construction materials cost team should have sufficient experience to calculate the cost. Information on prices and production rates must be updated to obtain the correct results to estimate the cost of building materials. If the cost estimate is incorrect, it will affect the final price of building materials

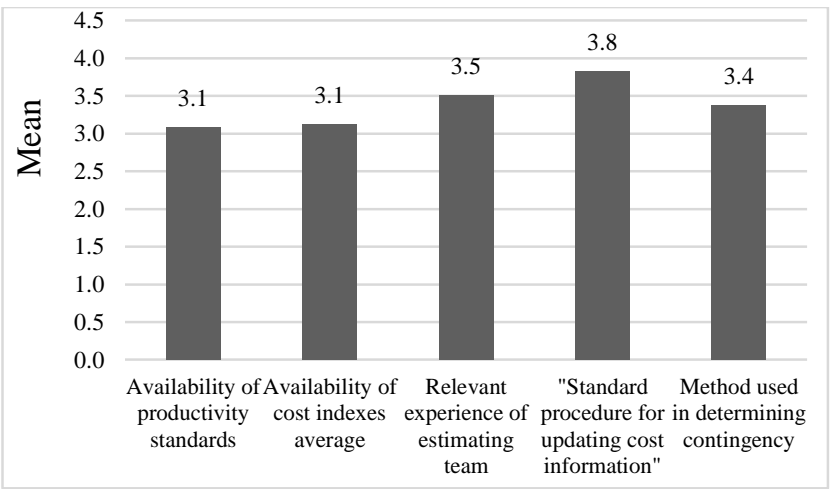

Figure (8) Estimating Process Factors

Figure (8) indicate that most of the respondents are moderately agree that all estimating process factors are responsible for cost overrun in construction materials, the result of ranking factors indicate that standard procedure for updating cost information has the highest in the ranking of estimating process-related factor analysis, relevant experience of estimating teams ranked the second among the issues outlined above, method used in determining contingency is occupied the third position, availability of productivity standards, availability of cost indexes average both are occupied the fourth position.

\subsection{Overall Material Mismanagement Factors}

Many researchers have discovered the reasons for the disparity between the tender sum and the final cost of construction cost. The following were identified as the factors that influence cost overruns. Such as design-related factors, client-related factors, contractor related factors, site-related factors, labor and equipment related factors, a market condition related factors, external factors, cost estimating team related factors. 


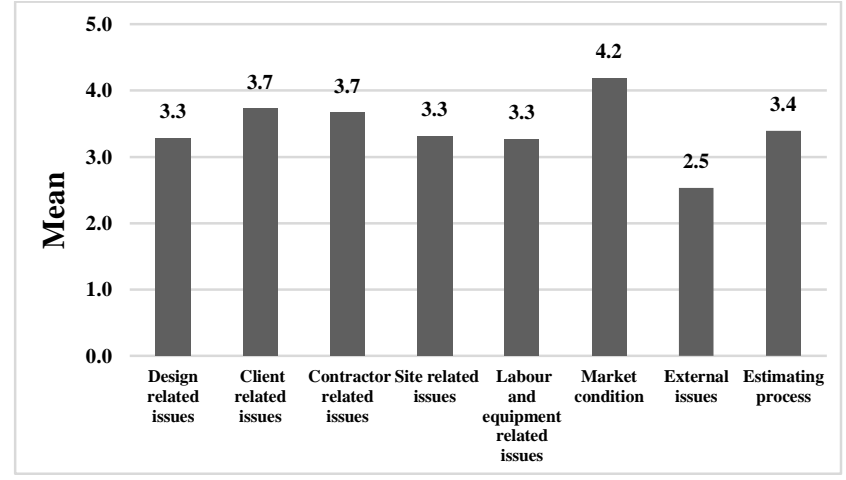

Figure (9) Categories Factors

Figure (9) indicate that most of the respondents are strongly agree the market condition factor is responsible for cost overrun in building materials at the same time they moderately agree that remaining factors increases the cost, the result of ranking factors indicate that the market condition factors have the highest in the ranking of factor analysis, Client related issues and contractor related issues factors both are ranked the second among the factors outline above, estimating process factors that occupied third position, design related issues, site related issues and labor and equipment related issues all are occupied the fourth position, external factors is lie at fifth rank in the above ranking of construction materials cost overrun.

\section{Important Factors}

By examining the important indices of each factor in section 7 it can be decided that some factors are heavily considered to have high impact. For example, Unsettlement of the local currency in relation to dollar value, fluctuation of the price of raw materials, project materials monopoly by some suppliers, poor contractor experience of project type, waste control during material usage. On the other hand, factors such as the inability to complete the design at the tender stage, weather condition, the problem with neighbors and design complexity, have low impact.

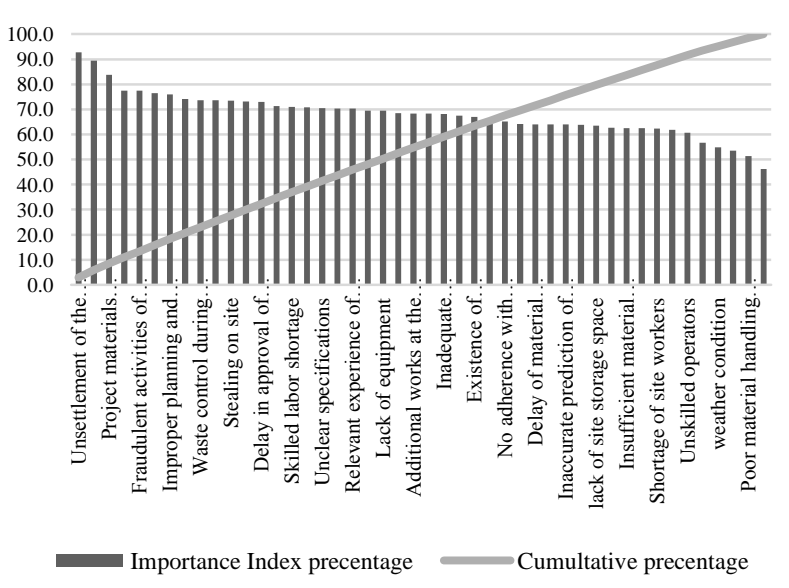

Figure (10) Pareto Analysis Chart
Pareto analysis technique assumes that $20 \%$ of factors can have the most important effect. Therefore, this percentage will lead us to the selection of the first nine factors as shown in Figure (10)

For more precision, the first twelve factors will be selected "factors with importance index higher than 73\%" as shown in Table (2).

Table (2) The important factors

\begin{tabular}{|l|c|c|}
\hline \multicolumn{1}{|c|}{ Factors } & RII & Rank \\
\hline $\begin{array}{l}\text { Unsettlement of the local currency in relation to the } \\
\text { dollar value }\end{array}$ & $93 \%$ & 1 \\
\hline Fluctuation of the price of raw materials & $89 \%$ & 2 \\
\hline Project materials monopoly by some suppliers & $84 \%$ & 3 \\
\hline Fraudulent activities of subcontractors & $78 \%$ & 4 \\
\hline Standard procedure for updating cost information & $77 \%$ & 5 \\
\hline Poor contractor experience of the project type & $77 \%$ & 6 \\
\hline Improper planning and errors during construction & $76 \%$ & 7 \\
\hline Engaging inadequate skill in labor & $74 \%$ & 8 \\
\hline Waste control during material usage & $74 \%$ & 9 \\
\hline Location of project & $74 \%$ & 10 \\
\hline Improper construction methods & $73 \%$ & 11 \\
\hline Improper supervision at site and control & $73 \%$ & 12 \\
\hline
\end{tabular}

\section{CONCLUSION}

Based on the analysis, obtained conclusions are given below

Identifying variables influencing construction materials cost overruns shows that, design issues, client issues, contractor issues, site issues, labor and equipment issues, market condition, external issues, estimating process issues are responsible for cost overrun of building construction projects are described.

The important factors that severely affect construction materials cost estimating accuracy were twelve factors. The biggest effect was unsettlement of the local currency in relation to the dollar value "inflation rate" and the smallest effect was improper supervision at site and control. Hence, construction parties could reduce the percentage of cost variance by the following:

1. Consider economic instability and project location when defining contingency value

2. Enhance the quality of planning and management of the project

3. Assign a project manager and estimating team with a long period of experience and good abilities

4. Apply good management, and financial plans

5. Provide enough numbers of labor and equipment

6. Use detailed estimates

7. Use accurate bidding documents 
8. Adhere to choose of construction methods.

9. Adhere to supervision at site and control.

10. Contracting with a highly experienced contractor

\section{REFERENCES}

1. Ailabouni, N. (2010). Factors affecting employee productivity in the UAE construction industry, University of Brighton.

2. Attalla, M. and T. Hegazy (2003). "Predicting cost deviation in reconstruction projects: Artificial neural networks versus regression." Journal of Construction Engineering and Management129(4): 405-411.

3. Baxter, J. and P. L. Bartlett (2001). "Infinite-horizon policy-gradient estimation." Journal of Artificial Intelligence Research15: 319-350.

4. Bernold, L. E. and J. F. Treseler (1991). "Vendor analysis for best buy in construction." Journal of Construction Engineering and Management117(4): 645-658.

5. Burroughs, S. E. and G. Juntima (2004). "Exploring techniques for contingency setting." International Transactions: ES31.

6. Cheung, S. O., et al. (2004). "PPMS: a web-based construction project performance monitoring system." Automation in construction13(3): 361-376.

7. Donyavi, S. and R. Flanagan (2009). The impact of effective material management on construction site performance for small and medium sized construction enterprises. Procs 25th Annual ARCOM Conference.

8. Durdyev, S. and J. Mbachu (2011). "On-site labour productivity of New Zealand construction industry: Key constraints and improvement measures." Construction Economics and Building11(3): 18-33.

9. El-Kholy, M. (2015). "Predicting cost overrun in construction projects." International Journal of Construction Engineering and Management4(4): 95105 .

10. Enshassi, A., et al. (2015). "Cost estimation practice in the Gaza Strip: A case study." IUG Journal of Natural Studies 15(2).

11. Iyer, K. and K. Jha (2005). "Factors affecting cost performance: evidence from Indian construction projects." International Journal of Project Management23(4): 283-295.

12. Kini, D. U. (1999). "Materials management: The key to successful project management." Journal of management in engineering15(1): 30-34.
13. Oberlender, G. D. and S. M. Trost (2001). "Predicting accuracy of early cost estimates based on estimate quality." Journal of Construction Engineering and Management127(3): 173-182.

14. Rajaprabha, R., et al. (2016). "Factors Affecting The Cost Of Building Material In Construction Projects." International Journal of Science and Engineering Research4: 1-6.

15. Rifai, H. and A. Soekiman (2014). "A Predictive Model of Project Success Measurement for Government Building Construction Projects (Case Study in Cirebon)."

16. Sonmez, R., et al. (2007). "Quantiative methodology for determination of cost contingency in international projects." Journal of management in engineering 23(1): 35-39.

17. Stukhart, G. (1995). Construction materials management.

18. Touran, A. (2003). "Probabilistic model for cost contingency." Journal of Construction Engineering and Management129(3): 280-284

19. Ugwu, O. and T. Haupt (2007). "Key performance indicators and assessment methods for infrastructure sustainability — a South African construction industry perspective." Building and environment42(2): 665-680.



